\title{
Acetylcholinesterase inhibition by medicinal plants: A Review
}

Navi Ranjan* and Manorma Kumari

Botany Department, A N College, Patna (Magadh University), Bihar-800013, India.

Received: 2017-05-04; Accepted: 2017-05-23

\begin{abstract}
Acetylcholinesterase (AChE), the predominant cholinesterase in the brain, hydrolyzes ACh to choline and acetate, thereby terminating the effect of this neurotransmitter at cholinergic synapses. Therefore, AChE is the target of cholinesterase inhibitors used for addressing the cholinergic deficit in Alzheimer's disease (AD) patients. Despite decades of research and advances in our understanding of its aetiology and pathogenesis, current pharmacotherapeutic options for $\mathrm{AD}$ are still very limited and represent an area of need that is currently unmet. The leading $\mathrm{AD}$ therapeutics involves AChE inhibitors, resulting in increased acetylcholine concentrations in the synaptic cleft and enhanced cholinergic transmission. Compounds showing an AChE inhibitory effect are also used for the treatment of senile dementia, myastenia gravis, Parkinson's disease and ataxia. Taking into account that the inhibition of AChE has been one of the most used strategies for treating $\mathrm{AD}$ and that existing drugs are effective only against mild to moderate type of disease while presenting considerable side effects, the search for new sources of effective and selective anti acetylcholinesterase agents with fewer side effects is imperative. Various plants and phytochemical substances have demonstrated AChE inhibitory activity and thus could be beneficial in the treatment of neurodegenerative disorders such as AD.
\end{abstract}

Keywords: Alzheimer's disease (AD); Acetylcholine (ACh); Acetylcholinesterase (AChE); Medicinal Plants.

\section{Introduction}

Inhibition of Cholinesterases, mainly Acetylcholinesterase (AChE) and therefore prevention of acetylcholine degradation in synapses of cholinergic system is one of the most accepted palliative therapy opportunities for Alzheimer's disease (AD) today [1]. Since the introduction of the first cholinesterase inhibitor in 1997, most clinicians would consider the cholinergic drugs, donepezil, rivastigmine [2], and galantamine [3], to be the first line pharmacotherapy for mild and moderate AD. The most that these drugs could achieve is to modify the manifestations of AD. Due to a lack of selectivity of cholinesterase inhibitor drugs on the market, AD-patients suffer from side effects like nausea or vomiting.

The enzyme acetylcholinesterase (AChE) catalyses the hydrolysis of the ester bond of acetylcholine (ACh) to terminate the impulse transmitted action of ACh through cholinergic synapses [4]. Although the basic reason of Alzheimer's disease (AD) is not clear so far, AD is firmly associated with impairment in cholinergic transmission. A number of AChE inhibitors have been considered as candidates for the symptomatic treatment of $\mathrm{AD}$ as the most useful relieving strategy [5].

Principal role of acetylcholinesterase (AChE) is the termination of nerve impulse transmission at the cholinergic synapses by rapid hydrolysis of acetylcholine (ACh). Inhibition of AChE serves as a strategy for the treatment of Alzheimer's disease
(AD), senile dementia, ataxia, myasthenia gravis and Parkinson's disease $[6,7,8]$. There are a few synthetic medicines, e.g. tacrine, donepezil, and the natural product based rivastigmine for treatment of cognitive dysfunction and memory loss associated with AD [9]. These compounds have been reported to have their adverse effects including gastrointestinal disturbances and problems associated with bioavailability [10,11], which necessitates the interest in finding better AChE inhibitors from natural resources.

\section{Acetylcholinesterase inhibitors from Plants}

Several reviews on the newly discovered AChE inhibitors obtained from plants, fungus and marine organisms have also been published over the last years [12-15]. The majority of these AChE inhibitors belong to the alkaloid group, including indole, isoquinoline, quinolizidine, piperidine and steroidal alkaloids. On the other hand, several nonalkaloidal and potent $\mathrm{AChE}$ inhibitors have been obtained from natural sources, including terpenoids, flavonoids and other phenolic compounds. Interestingly, although literature demonstrates to be rich in the study on AChE inhibitors obtained from plants, this issue keeps on being the centre of attention for research as confirmed by the increasing number of studies published every year.

Methanolic extracts of seven herbs Acorus calamus, Acorus gramineus, Bupleurm facaltum, Dioscorea batatas, Epimedium koreanum, Poria cocos and Ziryphi jujuba,

\footnotetext{
*Corresponding Author:

Dr. Navi Ranjan,

Department of Botany,

A N College, Patna (Magadh University),

Bihar-800013, India.

E-mail: naviranjan1985@gmail.com
}

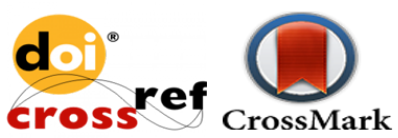


used in traditional Korean medicine for improvement of memory and cognition in old age have been tested for cholinesterase inhibitory properties and significant inhibition of the enzyme was shown by extracts from Acorus calamus and $E$. koreanum [9,16,17] screened the methanolic extracts of 32 plants used in Thai traditional rejuvenating and neurotonic remedies, for inhibitory activity on $\mathrm{AChE}$ and found that the extracts from roots of Stephania suberosa and Tabernaemontana divaricata showed significant inhibitory activity.

Aqueous and methanol extracts of 11 plants, used in Danish folk medicine for improvement of memory and cognition, and three Corydalis species have been tested for their AChE inhibitory activity [18]. The authors reported significant dosedependent inhibitory activity for extracts of the Corydalis species whereas only moderate inhibition of the enzyme was observed for extracts of Ruta graveolens L., Lavandula augustifolia Miller, Rosmarinus officinalis L., Petroselinum crispum (Mil.) Nym. ex A. W. Hill., and Mentha spicata L. The latter five species contain essential oils with terpenes, a group of compounds reported to have AChE inhibitory activity $[19,18]$.

The history of drug discovery has shown that plants contain active compounds that have become new sources to investigate for the pharmaceutical industry. Plant constituents may not only act synergistically with other constituents from the same plant but may also enhance the activity of compounds or counteract toxic effects of compounds from other plant species [20]. In traditional practices, numerous plants have been used to treat cognitive disorders, including neurodegenerative diseases and different neuropharmacological disorders [21]. Yokukansan, a Chinese herbal remedy which is used to treat various neurological states has been reported as being effective with no adverse effects [22]. Also, galanthamine, an alkaloid from snowdrop, has been approved by the Food and Drug Administration in the United States for use in the treatment of Alzheimer's disease [17,23]. Since AD has become a public health burden, and the commonly available synthetic drugs have undesirable side-effects, new treatment strategies based on medicinal plants have been the subject of current focus.

Black pepper (Piper nigrum), is one of the oldest and most popular spices in the world. It belongs to the family Piperaceae and is used in many Asian countries. It is used in folk medicine for stomach disorders, digestive problems, and neuralgia and as CNS depressant [24]. Its active constituent, piperine, has been reported to significantly improve memory impairment and neurodegeneration in hippocampus. Moreover, piperine also demonstrated the neurotrophic effect in hippocampus [25]. Cumin (Cuminum cyminum) is an aromatic plant, belongs to Apiaceae family. It is used to flavour foods and used in many medicinal preparations. It has been used as an astringent, as carminative and eupeptic as well as an analgesic agent [26]. Cumin extract has also been known to possess antistress, antioxidant and memoryenhancing activity [27].

Sedge or Cyperus rotundus belongs to the family Cyperaceae. The rhizome of Cyperus is rich in essential oils that contain pinene, a little cineole, terpenes, and a new alcohol called isociprol. Several chemical components have been isolated from ethanol extract of $C$. rotundus rhizome and some of these chemicals possess anti-AChE activity [28]. Gingko biloba extract significantly inhibit the $\mathrm{AChE}$ activity in the brain. The inhibition of AChE activity can be correlated with improvement observed in scopolamine-induced deficits in passive avoidance by $G$. biloba extract. The decrease in AChE activity indicates an increase in the basal level of acetylcholine [29].

Morinda citrifolia ( $M$. citrifolia) fruit and extract have analgesic, anti-inflammatory and antioxidant properties [30]. Ethyl acetate extract of $M$. citrifolia prevented memory deficit and oxidative stress induced by amyloid beta peptide in mice [31]. Treatment with chloroform, ethyl acetate and butanol extracts of $M$. citrifolia in a dose-dependent manner reduced AChE enzyme activity in the brain of scopolamine-treated mice. In addition, scopolamine-induced amnesia is associated with decreased cerebral blood flow and increased oxidative stress and AChE activity in rat brain, and treatment with the $M$. citrifolia extract improved scopolamine induced memory impairment in the shuttle box test [30].

Desmodium gangeticum DC belongs to family Leguminosae. Extract of the root and leaves of $D$. gangeticum inhibited acetyl-cholinesterase enzyme activity in mid brain, cerebellum, medulla and cortex of mice brain [32]. Desmodium gangeticum, commonly known as "Salpan", "Salpani" in Hindi and "Shalparni" in Sanskrit, is used in Ayurveda, Siddha and Unani systems of medicine. It is a bitter tonic, febrifuge, digestive, anticatarrhal, antiemetic also used in inflammatory conditions of chest and in various other inflammatory conditions which are due to "vata" disorder. Its roots have been used as expectorant and in snake bite and scorpion sting. It is an ingredient of Ayurvedic preparations like "Dashmoolarishta" and "Dashmoolakwaath" recommended for post-natal care to avoid secondary complications [33]. Embelia ribes Burm belongs to family Myrsinaceae also inhibit acetylcholinesterase. Azadirachta indica belongs to family Meliaceae, aqueous extract from bark of $A$. indica inhibit the AChE activity by in vitro methods [34]. Ficus racemosa belongs to family Moraceae; cold 
and hot aqueous extracts of Ficus racemosa stem bark showed AChE inhibitory activity against rat brain acetylcholineterase in vitro [35].

Cinnamomum zeylanicum has been used as a spice as well as traditional medicine for many centuries. It possesses many unique medicinal properties such as sugar control, anti-oxidant, anti-inflammatory and antimicrobial activity [36]. Cinnamon extract has been found to have an inhibitory effect on tau aggregation related to Alzheimer's disease (AD). The extract can also promote complete disassembly of recombinant tau filaments and cause substantial alteration of the morphology of paired-helical filaments isolated from $\mathrm{AD}$ brain [37]. In a recent study, orally administered cinnamon extract has been found to reduce $\beta$-amyloid oligomerization and correct cognitive impairment in $\mathrm{AD}$ animal models [38]. Eugenia caryophyllus (clove), belonging to the family Myrtaceae, has a number of medicinal properties. Clove has been reported to possess a potent anti-oxidant activity in vitro, which reduces the oxidative stress in the body [39]. Clove oil has been reported to reverses learning and memory deficits in scopolamine treated mice [40]. The aqueous extract of Eugenia caryophyllus has also been found to possess AChE inhibitory activity in rats. It reduces the hydrolysis of ACh by AChE [41].

The chief chemical constituent of the Galanthus nivalis L. (common snowdrop) is Galanthamine, and this is an isoquinoline alkaloid. Galanthamine has been found to be the long-acting and specific inhibitor of the AChE enzyme and to potentiate cholinergic nicotinic neurotransmission by allosterically modulating the nicotinic acetylcholine receptors, which may be of additional value in the treatment of AD [42,43]. Huperzia serrata (Thunb. ex Murray) is one of the genera in the Huperziaceae family (syn. Lycopodiaceae family). This genus, has been used for its memory-enhancing effect since ages in the Traditional Chinese Medicinal system (TCM), and is known to contain a large group of alkaloids called 'Lycopodium alkaloids'. Huperzine A, a novel Lycopodium alkaloid extracted from Huperzia serrata, is well known as a reversible, potent, and selective $\mathrm{AChE}$ inhibitor. It is also known as 'Qian Ceng Ta' in China, and Huperzine A has been used as a therapeutic agent for AD from centuries [44]. Tinospora Cordifolia (Guduchi) possesses a memory enhancing property for learning and memory in normal and memorydeficits animals. Tinospora Cordifolia's mechanism for cognitive enhancement is by immunostimulation and synthesis of acetylcholine, this supplementation of choline enhances the cognitive function [45].

\section{Conclusion}

Acetylcholine is a neurotransmitter that plays a key role in cognitive function and reasoning. The brains of those with mild-to-moderate Alzheimer's disease, a progressive type of dementia, have abnormally low acetylcholine concentrations. This means that any compound that enhances the cholinergic system in the brain may be useful in treating Alzheimer's disease and similar brain malfunctions.

Herbs may play a promising role in the early treatment of Alzheimer's and other conditions involving poor memory and dementia. One of the chief benefits is that they have a low toxicity compared to pharmaceutical agents. A review of the literature indicates that the sooner the treatment is started; the better will be the outcome. Therefore, if clients have family members with a history of Alzheimer's disease, or other states involving poor memory, they may start taking these remedies prior to the onset of symptoms, to delay or possibly prevent the advent of the symptoms. The use of herbal medicines in the treatment of AD should be compared with the pharmacological treatment currently in use. Such studies should include identification of the active principle in order to improve the validation of the clinical trial. Further large-scale, multicenter studies are necessary to determine the effectiveness of these substances in the cognitive deterioration of AD. Until then, this review provides some evidence of the benefit of a wide range of herbs (included in the Indian Medicine System, Chinese Medicine System, European Medicine System, etc.) in the treatment of $\mathrm{AD}$.

\section{Acknowledgments}

The Authors are thankful to University Grants Commission, New Delhi for grant as Major Research Project. File No-43-114/2014(SR).

\section{References}

1. Birks J. Cholinesterase inhibitors for Alzheimer's disease. Cochrane Database Syst Rev. 1. (2006):CD005593

2. Birks J, J Grimley Evans, V Iakovidou, M Tsolaki, FE Holt. Rivastigmine for Alzheimer's disease. Cochrane Database Syst Rev 2. (2009):CD001191.

3. Prvulovic D, H Hampel, J Pantel. Galantamine for Alzheimer's disease. Expert Opin Drug Metab Toxicol. 6.3 (2010): 345-354.

4. Stryer L. Biochemistry. 4th ed., WH Freeman: San Francisco, CA, (1995): 1017.

5. Howes MJR, NSL Perry, PJ Houghton. Plants with traditional uses and activities, relevant to the management of Alzheimer's disease and other cognitive disorders. Phytother Res. 7 (2003): 1-18.

6. Anonymous. Compendium of Pharmaceuticals and Specialties, 25th ed. Canadian Pharmacists Association, Toronto, Canada. (2000).

7. Brenner GM. Pharmacology. W.B. Saunders Company, Philadelphia. (2000). 
8. Rahman AU, MI Choudhary. Bioactive natural products as a potential source of new pharmacophores a theory of memory. Pure Appl. Chem. 73 (2001): 555-560.

9. Oh MH, PJ Houghton, WK Whang, JH Cho. Screening of Korean herbal medicines used to improve cognitive function for anti-cholinesterase activity. Phyto-medicine 11(2004): 544-548.

10. Schulz V. Ginkgo extract or cholinesterase inhibitors in patients with dementia: what clinical trial and guidelines fail to consider. Phytomedicine .10(2003): 74-79.

11. Melzer D. New drug treatment for Alzheimer's diseases: lessons for healthcare policy. BMJ 316 (1998): 762-764.

12. Houghton PJ, Y Ren, MJ Howes. Acetylcholinesterase inhibitors from plants and fungi. Nat. Prod. Rep. 23 (2006): 181-199.

13. Williams P, A Sorribas, MJ Howes. Natural Products as a source of Alzheimer's drugs leads. Nat. Prod. Rep. 28 (2011): 48-77.

14. Mukherjee PK, V Kumar, M Mal, PJ Houghton. Acetylcholinesterase inhibitors from plants. Phytomedicine 14 (2007): 289-300.

15. Orhan G, I Orhan, N Subutay-Oztekin, F Ak, B Sener. Contemporary anticholinesterase pharmaceuticals of natural origin and their synthetic analogues for the treatment of Alzheimer's disease. Recent. Pat. CNS Drug. Discov. 4 (2009): 43-51.

16. Ingkaninan $\mathrm{K}, \mathrm{D}$ Best, VD Heijden, AJP Hofte, B Karabatak, H Irth, UR Tjaden, VD Greef, R Verpoorte. High-performance liquid chromatography with on-line coupled UV, mass spectrometric and biochemical detection for identification of acetylcholines-terase inhibitors from natural products. J. Chromatogr. A 872 (2000): 61-73.

17. Ingkaninan $\mathrm{K}, \mathrm{P}$ Temkitthawon, $\mathrm{K}$ Chuenchom, $\mathrm{T}$ Yuyaem, W Thongnoi. Screening for acetylcholinesterase inhibitory activity in plants used in Thai traditional rejuvenating and neurotonic remedies. J. Ethnopharmacol. 89 (2003): 261-264.

18. Adsersen A, B Gauguin, L Gudiksen, AK Jager. Screening of plants used in Danish folk medicine to treat memory dysfunction for acetylcholinesterase inhibitory activity. J. Ethnopharmacol. 104 (2006): 418422.

19. Perry NSL, PJ Houghton, AE Theolad, P Jenner, EK Perry. In vitro inhibition of human erythrocyte acetylcholinesterase by Sal via lavandulaefolia essential oil and constituent terpenes. J. Pharm. Pharmacol. 52 (2000): 895-902.

20. Howes MJ, PJ Houghton. Plants used in Chinese and Indian traditional medicine for improvement of memory and cognitive function. Pharmacol. Biochem. Behav. 75 (2003): 513-527.
21. Mukherjee PK, V Kumar, M Mal, PJ Houghton. Acetylcholinesterase inhibitors from plants. Phytomedicine 14 (2007a): 289-300.

22. De Caires S, V Steenkamp. Use of Yokukansan (TJ54) in the Treatment of Neurological Disorders: A Review. Phytother. Res. (2010) Doi: 10.1002/ptr.3146.

23. Heinrich $\mathrm{M}, \mathrm{HL}$ Teoh. Galanthamine from snowdrop-the development of a modern drug against Alzheimer's disease from local Caucasian knowledge. J. Ethnopharmacol. 92 (2004): 688-697.

24. Singh R, N Singh, BS Saini, HS Rao. In vitro antioxidant activity of pet ether extract of black pepper. Indian J Pharmacol .40. 4 (2008):147-51.

25. Chonpathompikunlert P, J Wattanathorn, S Muchimapura. Piperine, the main alkaloid of Thai black pepper, protects against neurodegeneration and cognitive impairment in animal model of cognitive deficit like condition of Alzheimer's disease. Food Chem Toxicol. 48.3 (2010):798-802.

26. De $\mathrm{M}, \mathrm{AK}$ De, $\mathrm{R}$ Mukhopadhay, AB Banerjee, $\mathrm{M}$ Micro. Antimicrobial activity of Cuminum cyminum $\mathrm{L}$. Ars Pharmaceutica 44 (2005):257-69.

27. Koppula S, DK Choi. Cuminum cyminum extract attenuates scopolamine-induced memory loss and stress- induced urinary biochemical changes in rats: a noninvasive biochemical approach. Pharm biol .49.7 (2011):702-8.

28. Sharma R, R Gupta. Cyperus rotundus extract inhibits acetylcholinesterase activity from animal and plants as well as inhibits germination and seedling growth in wheat and tomato. Life Sci. 80.24-25 (2007): 23892392.

29. Das A, G Shanker, C Nath, R Pal, S Singh, H Singh. A comparative study in rodents of standardized extracts of Bacopa monniera and Ginkgo biloba: anticholinesterase and cognitive enhancing activities. Pharmacol Biochem Behav 73.4 (2002): 893-900.

30. Pachauri SD, S Tota, K Khandelwal, PR Verma, C Nath, K Hanif et al. Protective effect of fruits of Morinda citrifolia $\mathrm{L}$. on scopolamine induced memory impairment in mice: a behavioral, biochemical and cerebral blood flow study. I Ethnopharmacol 139.1 (2012): 34-41.

31. Muralidharan P, VR Kumar, G Balamurugan. Protective effect of Morinda citrifolia fruits on $\beta$ amyloid induced cognitive dysfunction in mice: an experimental and biochemical study. Phytother Res 24.2(2010): 252-258.

32. Hanumanthachar J, P Milind. Pharmacological Evidences for the Antiamnesic Effects of Desmodium gangeticum in mice. Iranian Journal of Pharmaceutical Research. 6.3 (2007):199-207.

33. Rastogi S, MM Pandey, AKS Rawat. An ethnomedicinal, phytochemical and pharmacological profile of Desmodium gangeticum (L.) DC. and 
Desmodium adscendens (Sw.) DC. Journal of Ethnopharmacology. 136 (2011): 283-296.

34. Kumar S, CJ Seal, EJ Okello. Kinetics of acetylcholinesterase inhibition by an aqueous extract of Withania somnifera roots. Intrenational journal of pharmacentical sciences and research. 2 .5 (2011): 11881192.

35. Borhade P, A Tankar, S Joshi, K Khandelwal. Pharmacological Review on Ficus racemosa linn. International Journal of Pharmaceutical Research and BioScience 1 .6 (2012): 51-66.

36. Dugoua JJ, D Seely, D Perri, K Cooley, T Forelli. From type 2 diabetes to antioxidant activity: a systematic review of the safety and efficacy of common and cassia cinnamon bark. Can J Physiol Pharmaco .85 (2007):837-847.

37. Peterson DW, RC George, F Scaramozzino, NE La Pointe, RA Anderson, DJ Graves, J Lew. Cinnamon extract inhibits tau aggregation associated with Alzheimer's disease in vitro. J Alsheimers Dis. 17.3 (2009):583-97.

38. Frydman-Marom A, A Levin, D Farfara, T Benromano, R Scherzer-Attali, S Peled et.al. Orally administered cinnamon extract reduces $\beta$-amyloid oligomerization and corrects cognitive impairment in AD animal models. PLoS One 6.1(2011): e16564.

39. Shobana S, KA Naidu. Antioxidant activity of selected India spices. Prostaglandin Leukotri Essent Fat Acids. 62.2 (2000):107-10.
40. Halder S, AK Mehta, R Kar, M Mustafa, PK Mediratta, KK Sharma. Clove oil reverses learning and memory deficits in scopolamine treated mice. Planta Med. 77.8 (2011):830-4.

41. Akinrimisi EO, AL Akinwande. Effect of aqueous extract of Eugenia caryophyllus on brain acetylcholinesterase in rats. West Afr J Pharmacol Drug Res. 2.2(1975):127-31.

42. Bores GM, FP Huger, W Petko, AE Mutlib, F Camacho, DK Rush et al., Pharmacological evaluation of novel Alzheimer's disease therapeutics: Acetylcholinesterase inhibitors related to galanthamine. J Pharmacol Exp Ther. 277 (1996):72838.

43. Ikay O, O Gurdal and S Bilge. An update on plantoriginated treatment for Alzheimer's disease. Ethnomedicine: A Source of Complementary Therapeutics Available from: http://www.holistictherapypractice.com. [Last accessed on 2011 Jul 25]. (2010): 245-65.

44. Lannert H, S Hoyer. Intracerebroventricular administration of streptozotocin causes long-term diminutions in learning and memory abilities and in cerebral energy metabolism in adult rats. Behav Neurosci. 112 (1998):1199-208.

\section{Cite this article as:}

Navi Ranjan and Manorma Kumari.

Acetylcholinesterase inhibition by Medicinal Plants: A

Review. Annals of Plant Sciences 6.6 (2017) pp. 1640-1644.

DOI: http://dx.doi.org/10.21746/aps.2017.06.003

Source of support: University Grants Commission, New Delhi, India.

\section{Conflict of interest: Nil}

